\title{
The role of squamous cell carcinoma antigen as a prognostic and predictive factor in carcinoma of uterine cervix
}

\author{
Bae Kwon Jeong, MD1, Doo Ho Choi, MD1', Seung Jae Huh, MD', Won Park, MD', \\ Duk Soo Bae, MD², Byoung-Gie Kim, MD² \\ Departments of ${ }^{1}$ Radiation Oncology, ${ }^{2}$ Obstetrics and Gynecology, Samsung Medical Center, \\ Sungkyunkwan University School of Medicine, Seoul, Korea
}

Purpose: Although the role of squamous cell carcinoma antigen (SCC-Ag) as a predictive and prognostic factor for uterine cervical cancer has been identified in previous studies, 1) the effective patient group of screening for recurrence with SCC-Ag, 2) the relationship between SCC-Ag and recurrence site, and 3) the relationship between the change of SCC-Ag and treatment outcome or recurrence have not been described.

Materials and Methods: The study included 506 patients with histologically proven uterine cervical cancer between January 1994 and December 2010. We determining the serum SCC-Ag level before treatment and after treatment, and conducted a retrospective review of the patients' records. We evaluated the sensitivity and specificity of SCC-Ag for the detection of tumor recurrence by comparing biochemical recurrence with clinical recurrence.

Results: The pretreatment SCC-Ag level and the proportion of patients over $1.5 \mathrm{ng} / \mathrm{mL}$ were higher in poor prognostic patient group. In the univariate and multivariate analysis, pretreatment SCC-Ag showed a statistically significant correlation with tumor size, International Federation of Gynecology and Obstetrics (FIGO) stage, pathology. In patients with biochemical recurrence vs. those without, 5 -year DFS and OS were 27.6 vs. $92.7 \%$ ( $p \leq 0.001)$ and 53.7 vs. $92.5 \%$ ( $p \leq 0.001)$, respectively.

Conclusion: Our study reconfirmed the known function of pretreatment SCC-Ag, but could not confirm the function of biochemical response as a predictive factor for treatment and as a prognostic factor. There was no statistically significant relationship between SCC-Ag level and recurrence site. We confirmed the role of SCC-Ag as a follow-up tool for recurrence of disease and which patient groups SCC-Ag was more useful for.

Keywords: Cervical cancer, Squamous cell carcinoma antigen, Predictive factor, Prognostic factor

\section{Introduction}

In women, cervical cancer is the third most commonly diagnosed cancer and the fourth leading cause of cancer death in females worldwide, accounting for $9 \%(529,800)$ of all new cancer cases and $8 \%(275,100)$ of all cancer deaths among

Received 19 September 2011, Revised 28 September 2011, Accepted 29 September 2011.

Correspondence: Doo Ho Choi, MD, Department of Radiation Oncology, Samsung Medical Center, Sungkyunkwan University School of Medicine, 50 Irwon-dong, Gangnam-gu, Seoul 135-710, Korea. Tel: +82-2-3410-2436, Fax: +82-2-34102619, E-mail: doho.choi@samsung.com

(c) This is an Open Access article distributed under the terms of the Creative Commons Attribution Non-Commercial License (http://creativecommons.org/ licenses/by-nc/3.0/) which permits unrestricted non-commercial use, distribution, and reproduction in any medium, provided the original work is properly cited.

www.e-roj.org 
females in 2008 [1,2].

Several features are prognostically important in cervical cancer, including the extension of tumor, lymph node involvement, tumor size, lymph vascular space invasion, and depth of stromal invasion by tumor cell $[3,4]$. Optimal management consists of precise staging and implementation of appropriate treatment followed by deliberate posttreatment surveillance, early detection of recurrence, and appropriate salvage therapy. Early detection of recurrence has been found to improve survival in previous studies [5-7].

Tumor marker was effective tool for early detection of recurrence. The serum squamous cell carcinoma antigen (SCC$\mathrm{Ag}$ ) level elevated in $28-88 \%$ of patients with squamous cell carcinoma, and were considered the most accurate serologic tumor markers for patients with uterine cervical carcinoma in diagnostic tool in staging, cost-effective tool for disease monitoring of therapy [8-10], and detection of recurrence $[11,12]$. The elevated basal SCC-Ag level have been associated with the advanced stage of disease $[13,14]$, Iymph node involvement $[15,16]$ and poor response to treatment as well as with poor survival and higher tumor recurrence during followup $[12,17,18]$ regardless of clinical setting. However, not in all suspected recurrent cervical cancer patients with an elevated level of serum SCC-Ag during follow-up were detected lesions in physical examination and traditional imaging tests. The increasing SCC-Ag level precedes clinical diagnosis of recurrence in $46-92 \%$ of cases with a lead time of $2-8$ months $[11,19]$.

Although the role of SCC-Ag as a predictive and prognostic factor has been identified in previous studies, 1) the effective patient group of screening for recurrence with SCC-Ag, 2) the relationship between $\mathrm{SCC}-\mathrm{Ag}$ and recurrence site, and 3 ) the relationship between the change of SCC-Ag and treatment outcome or recurrence has not been described. This paper was designed to report these solutions and confirm the function of SCC-Ag.

\section{Materials and Methods}

The study included 506 patients who received radiotherapy sampled from 1,610 patients with histologically proven uterine cervical cancer, between January 1994 and December 2010. We analyzed information regarding age, menopausal status, International Federation of Gynecology and Obstetrics (FIGO) stage, pathology, tumor size, lymph node involvement, pretreatment and posttreatment SCC-Ag level, and sites of recurrence. The median age was 52.0 years (range, 23 to 85 years).

Inclusion criteria comprised of: 1) biopsy-confirmed cervical cancer of clinical stage I-IV of the FIGO staging system, 2) received definitive or postoperative radiotherapy combined with or without chemotherapy or surgery in any sequence, and 3) measures of serum squamous cell carcinoma antigen level before and after treatment.

All the patients underwent routine clinical staging. Additional image work-ups including abdominopelvic computed tomography (CT) and magnetic resonance imaging (MRI) were performed in all the patients before and after the completion of therapy. Lymph nodes greater than $1 \mathrm{~cm}$ in the greatest diameter were interpreted as being involved in image workups. We collected serum samples from each of all the patients for determining the serum SCC-Ag level before treatment and after treatment, and conducted a retrospective review of the patients' records. Serum SCC-Ag was measured using a SCC kit (Imx, Abbott Diagnostics, Illinois, USA) immunoradiometric assay. The lower level of sensitivity of this system was 0.1 $\mathrm{ng} / \mathrm{mL}$. We used $1.5 \mathrm{ng} / \mathrm{mL}$ of SCC-Ag level as the basis for classification. Biochemical response was defined by only changes of SCC-Ag level to treatment whether pre-treatment SCC-Ag level was in normal range or increased positive biochemical response was defined as SCC-Ag was reduced in comparison with pretreatment SCC-Ag and the rest were defined as negative. Biochemical failure was defined as two consecutive increases in the SCC-Ag values above $1 \mathrm{ng} / \mathrm{mL}$ than immediately before or elevation above $1.5 \mathrm{ng} / \mathrm{mL}$.

One hundred and eighty patients received concurrent chemoradiotherapy, 189 patients received curative surgery and then adjuvant concurrent chemoradiotherapy, 99 patients received curative surgery and then adjuvant radiotherapy, and 38 patients received radiation alone.

After treatment completion, all patients were assessed for response after a period of time to allow maximal regression of the tumor by WHO criteria. Complete response was defined as the complete disappearance of all visible or palpable tumor, partial response as a 50\% or greater reduction in the total tumor burden of the measurable lesions, stable disease as no change or less than 50\% reduction, and progressive disease as any increase in size of measurable lesions or the appearance of new lesions during treatment. The median length of followup for all the patients was 36.3 months (range, 2.2 to 159.9 months). Clinical examination, Pap smears, serum SCC-Ag, and image work-up including CT or MRI were performed after 
the completion of therapy. Abdominopelvic MRI and CT scan were done before and after treatment, and then scheduled individually according to clinical findings or elevated serum SCC-Ag level. During the clinical follow-up examinations, if a patient showed a biochemical failure without evidence of local recurrence possible sites of recurrence were checked systemically. Recurrent disease was used to indicate the reappearance of disease in patients who experienced complete response. The initial site of recurrence was categorized as locoregional recurrence (LRR) or distant metastasis (DM) based on the true pelvis.

We evaluated the sensitivity and specificity of SCC-Ag for the detection of tumor recurrence by comparing biochemical recurrence with clinical recurrence. The sensitivity and specificity of SCC-Ag were calculated using the following formulas:

$$
\begin{aligned}
& \text { Sensitivity }=\frac{\text { Number of true positives }}{\text { Number of true positives }+ \text { Number of false negatives }} \\
& \text { Specificity }=\frac{\text { Number of true negatives }}{\text { Number of true negatives + Number of false positives }}
\end{aligned}
$$

Statistical analyses were performed using ROC curves were used to determine the best cut-off points for serum SCCAg level. Analysis of the distribution of pretreatment and posttreatment SCC-Ag level according to clinicopathological characteristics was performed by the chi-square test or Fisher's exact test, Mann-Whitney test, and Spearman's correlation analysis. Multiple logistic regression models were used to identify independent prognostic factors for patients' response. Disease-free survival (DFS) was calculated from the date of initial treatment to the date of relapse of disease or the date of last follow-up and overall survival (OS) was calculated from the date of initial treatment to the date of death from disease or the date last seen. DFS and OS were calculated by the KaplanMeier method. A stepwise Cox proportional hazards model was used to determine the relation of clinicopathological parameters and SCC-Ag level in multivariate analysis. Logrank test was used to find the statistical significance and $p<$ 0.05 was considered significant. Statistical software SPSS ver. 18.0 (SPSS Inc., Chicago, IL, USA) was used for all statistical analyses.

\section{Results}

Table 1 shows the characteristics of the patients. The

\begin{tabular}{|c|c|}
\hline Characteristics & Value \\
\hline Age (yr) & 23-85 (median, 52.0) \\
\hline \multicolumn{2}{|l|}{ Menopausal status } \\
\hline Premenopause & $237(46.8)$ \\
\hline Menopause & $269(53.2)$ \\
\hline \multicolumn{2}{|l|}{ FIGO stage } \\
\hline I & $205(40.5)$ \\
\hline ॥ & $239(47.2)$ \\
\hline III & $40(7.9)$ \\
\hline IV & $22(4.3)$ \\
\hline \multicolumn{2}{|l|}{ Pathology } \\
\hline so & $433(85.6)$ \\
\hline$A D$ & $44(8.7)$ \\
\hline ASO & $17(3.4)$ \\
\hline Other & $12(2.4)$ \\
\hline Tumor size $(\mathrm{cm})$ & $0.2-15.0($ median, 4.1$)$ \\
\hline$\leq 4$ & $243(48.0)$ \\
\hline$>4$ & $254(50.2)$ \\
\hline Not & $9(1.8)$ \\
\hline \multicolumn{2}{|l|}{ Lymph node involvement } \\
\hline Positive & $286(56.5)$ \\
\hline Negative & $220(43.5)$ \\
\hline SCC-Ag (pretreatment; ng/mL) & $0.1-362.0($ mean, 3.1) \\
\hline$<1.5$ & $152(30.0)$ \\
\hline$\geq 1.5$ & $354(70.0)$ \\
\hline SCC-Ag (posttreatment; ng/mL) & $0.1-9.4$ (mean, 0.8) \\
\hline CCRT & $3.6(0.1-115.8)$ \\
\hline Triple & $2.7(0.3-133.6)$ \\
\hline OP-RT & $3.3(0.1-362.0)$ \\
\hline RT alone & $2.3(0.4-65.1)$ \\
\hline \multicolumn{2}{|l|}{ Response to treatment } \\
\hline$C R$ & $463(91.5)$ \\
\hline$P R$ & $23(4.5)$ \\
\hline PD & $1(0.2)$ \\
\hline Not & $19(3.8)$ \\
\hline \multicolumn{2}{|l|}{ Recurrence } \\
\hline Positive & $77(15.2)$ \\
\hline Negative & $429(84.8)$ \\
\hline \multicolumn{2}{|l|}{ Recurrent site } \\
\hline LRR & $33(42.9)$ \\
\hline $\mathrm{DM}$ & $38(49.4)$ \\
\hline $\mathrm{LRR}+\mathrm{DM}$ & $6(7.8)$ \\
\hline \multicolumn{2}{|l|}{ Biochemical response } \\
\hline Positive & $412(81.3)$ \\
\hline Negative & $94(18.6)$ \\
\hline
\end{tabular}

Table 1. Patient characteristics

median age was 52 years (range, 23 to 85 years), and 237 patients (46.8\%) were premenopausal while 269 (53.2\%) were menopausal status. FIGO stages were distributed as follows: $205(40.5 \%)$ in stage I, $239(47.2 \%)$ in stage II, 40 (7.9\%) 
Table 1. Continued

\begin{tabular}{lr}
\hline \multicolumn{1}{c}{ Characteristics } & Value \\
\hline Biochemical recurrence & \\
Positive & $82(16.2)$ \\
Negative & $424(83.8)$ \\
\hline
\end{tabular}

Values are presented as number (\%) unless otherwise indicated. FIGO, International Federation of Gynecology and Obstetrics; $S O$, squamous cell carcinoma; $A D$, adenocarcinoma; $A S O$, adenosquamous cell carcinoma; SCC-Ag, squamous cell carcinoma antigen; CCRT, concurrent chemoradiotherapy; $C R$, complete remission; $P R$, partial remission; $P D$, progression disease; $L R R$, locoregional recurrence; DM, distant metastasis.

in stage III, and 22 (4.3\%) in stage IV. As to pathological characteristics, 433 patients (85.6\%) had squamous cell carcinoma, 44 (8.7\%) had adenocarcinoma, and 17 (3.4\%) had adenosquamous cell carcinoma. Tumor size ranged between $0.2-15.0 \mathrm{~cm}$ (median, $4.1 \mathrm{~cm}$ ), and when the patients were classified based on $4 \mathrm{~cm}$, the classification criteria of FIGO stage, 243 patients (48.0\%) was smaller than $4 \mathrm{~cm}$ and 254 (50.2\%) exceeded $4 \mathrm{~cm}$. The numbers of patients with lymph node involvement and those without were 220 (43.5\%) and 286 patients (56.5\%), respectively. The pretreatment level of SCC-Ag showed a range of 0.1-362.0 ng/mL (mean, 3.1 $\mathrm{ng} / \mathrm{mL}$ ), and based on $1.5 \mathrm{ng} / \mathrm{mL}$ as the cutoff values of our hospital, 152 patients (30.0\%) were less than $1.5 \mathrm{ng} / \mathrm{mL}$ and $354(70.0 \%)$ were $1.5 \mathrm{ng} / \mathrm{mL}$ and more. The posttreatment level of SCC-Ag ranged between 0.1-9.4 ng/mL (mean, $0.8 \mathrm{ng} /$ $\mathrm{mL}$ ). As to the response to treatment, 463 patients (91.5\%) showed complete response, 23 (4.5\%) partial response, and 1 (0.2\%) progression disease, and for 19 patients (3.8\%) the result of treatment could not be assessed for lack of record. Recurrence was observed in 77 patients (15.2\%) and the site of recurrence was LRR in 33 patients (42.9\%), DM in 38 (49.4\%), and simultaneous LRR and DM in 6 (7.8\%). The posttreatment SCC-Ag was measured in all patients, 412 (81.3\%) showed a positive response and 94 (18.6\%) showed a negative response. Biochemical recurrence defined in this study was confirmed in 82 patients (16.2\%).

Table 2 shows the median and range of pretreatment SCC$\mathrm{Ag}$ level measured according to patient-related and diseaserelated factors, and the proportion of patients whose SCC-Ag level was over $1.5 \mathrm{ng} / \mathrm{mL}$. The median pretreatment SCC-Ag level was no significant difference between the each patient group except of recurrent site. The proportion of patients over $1.5 \mathrm{ng} / \mathrm{mL}$ were higher in the patient groups of menopausal status, higher FIGO stage, squamous cell carcinoma, large tumor size, positive lymph node involvement, partial response to treatment, recurrence of disease, DM, positive biochemical response, and positive biochemical recurrence compared to the other groups. Table 3 summarized the sensitivity and specificity of SCC-Ag in each group of patient, by comparing the biochemical recurrence with clinical recurrence. The sensitivity was from $35.0 \%$ in patient with $1.5 \mathrm{ng} / \mathrm{mL}$ or more pretreatment SCC-Ag to $100 \%$ in patients with simultaneously LRR and DM. Specificity was a little over $81.8 \%$ in patients at FIGO stage III, and except for this group it was around of $90 \%$ in most of the patients. In case of true positive patients who had actual recurrence among those whose biochemical recurrence was positive, the time interval from the biochemical recurrence to the clinical recurrence, namely, the leading time was 1 month in median and 0-4.6 months in range.

Table 4 summarized the results of univariate analysis for pretreatment and posttreatment SCC-Ag. In the results of univariate analysis, pretreatment SCC-Ag showed a statistically significant correlation with age, menopausal status, tumor size, lymph node involvement, pathology, FIGO stage, biochemical response, biochemical recurrence and response to treatment, but posttreatment SCC-Ag was not significant correlation with any factors. Table 5 summarized the results of multivariate analysis on pre-treatment SCC-Ag, recurrence of disease, and biochemical recurrence. In the results, pretreatment SCC$\mathrm{Ag}$ was in a statistically significant correlation with tumor size, FIGO stage and pathology, and recurrence of disease with pathology and response to treatment, and biochemical recurrence with posttreatment SCC-Ag.

Table 6 shows 5 -year OS and DFS in relation to pretreatment SCC-Ag, biochemical response and biochemical recurrence. In patients with pre-treatment SCC-Ag $<1.5 \mathrm{ng} / \mathrm{mL}$ vs. those $\geq$ $1.5 \mathrm{ng} / \mathrm{mL}$, 5-year DFS and OS were 82.3 vs. $77.9 \%(p=0.221)$ and 88.5 vs. $82.4 \%(p=0.128)$, respectively, and in patients showing positive vs. negative biochemical response, 5 -year DFS and OS were 78.4 vs. 83.2 ( $p=0.492$ ) and 83.6 vs. 87.1 ( $p$ $=0.542$ ), respectively. In patients with biochemical recurrence vs. those without, 5-year DFS and OS were 27.6 vs. $92.7 \%$ ( $p \leq$ $0.001)$ and 53.7 vs. $92.5 \%(p \leq 0.001)$, respectively.

\section{Discussion and Conclusion}

Extension of tumor, lymphovascular space invasion, depth of stromal invasion by tumor cell, FIGO stage, tumor size, and lymph node status have been recognized as important 
Table 2. The pretreatment level of SCC-Ag $(\mathrm{ng} / \mathrm{mL})$

\begin{tabular}{|c|c|c|}
\hline Characteristics & Median (range) & $\geq 1.5 \mathrm{ng} / \mathrm{mL}(\%)$ \\
\hline All & $3.1(0.1-362.0)$ & $354 / 506(70.0)$ \\
\hline \multicolumn{3}{|l|}{ Menopausal status } \\
\hline Premenopause & $3.0(0.1-362.0)$ & $149 / 237(62.9)$ \\
\hline Menopause & $3.3(0.1-133.6)$ & $205 / 269$ (85.8) \\
\hline \multicolumn{3}{|l|}{ FIGO stage } \\
\hline । & $3.4(0.1-362.0)$ & $111 / 205(54.1)$ \\
\hline ॥ & $2.6(0.1-115.8)$ & $187 / 239(78.2)$ \\
\hline III & $4.5(0.6-38.0)$ & $35 / 40(87.5)$ \\
\hline IV & $2.4(0.3-60.2)$ & $21 / 22(95.5)$ \\
\hline \multicolumn{3}{|l|}{ Pathology } \\
\hline so & $3.1(0.1-362.0)$ & $334 / 433(77.1)$ \\
\hline$A D$ & $4.8(0.4-41.8)$ & $7 / 44(15.9)$ \\
\hline ASO & $3.3(0.1-79.3)$ & $11 / 17(64.7)$ \\
\hline Other & $3.3(0.5-49.9)$ & $2 / 12(16.7)$ \\
\hline \multicolumn{3}{|l|}{ Tumor size (cm) } \\
\hline$\leq 4$ & $3.1(0.1-362.0)$ & $150 / 243(61.2)$ \\
\hline$>4$ & $3.1(0.1-115.8)$ & $200 / 254(78.7)$ \\
\hline Not & $5.8(0.2-53.3)$ & $4 / 9(44.4)$ \\
\hline \multicolumn{3}{|c|}{ Lymph node involvement } \\
\hline Positive & $3.0(0.1-133.6)$ & $215 / 286(75.1)$ \\
\hline Negative & $3.1(0.1-362.0)$ & $139 / 220(63.2)$ \\
\hline \multicolumn{3}{|c|}{ Response to treatment } \\
\hline$C R$ & $3.0(0.1-362.0)$ & $142 / 322(44.1)$ \\
\hline$P R$ & $6.2(0.7-61.0)$ & $21 / 23(91.3)$ \\
\hline Not & $6.3(0.4-115.8)$ & $11 / 20(55.0)$ \\
\hline \multicolumn{3}{|l|}{ Recurrence } \\
\hline Positive & $2.3(0.4-68.0)$ & $58 / 77$ (75.3) \\
\hline Negative & $3.1(0.1-362.0)$ & $296 / 429(69.0)$ \\
\hline \multicolumn{3}{|l|}{ Recurrent site } \\
\hline LRR & $5.2(0.4-50.2)$ & $23 / 34(67.6)$ \\
\hline DM & $1.7(0.4-68.0)$ & $30 / 38$ (78.9) \\
\hline$L R R+D M$ & $1.5(0.6-46.0)$ & $5 / 6(83.3)$ \\
\hline \multicolumn{3}{|c|}{ Biochemical response } \\
\hline Positive & $3.1(0.1-362.0)$ & $341 / 412(82.8)$ \\
\hline Negative & $2.6(0.1-133.6)$ & $13 / 94(13.8)$ \\
\hline \multicolumn{3}{|c|}{ Biochemical recurrence } \\
\hline Positive & $3.0(0.4-60.2)$ & 65/82 (79.3) \\
\hline Negative & $3.1(0.1-362.0)$ & $289 / 424(68.2)$ \\
\hline
\end{tabular}

SCC-Ag, squamous cell carcinoma antigen; FIGO, International Federation of Gynecology and Obstetrics; SO, squamous cell carcinoma $A D$, adenocarcinoma; $A S Q$, adenosquamous cell carcinoma; $C R$, complete remission; $P R$, partial remission; LRR, locoregional recurrence; $\mathrm{DM}$, distant metastasis.

predictors of patient survival $[3,4]$. It has also been reported that proportion of $1.5 \mathrm{ng} / \mathrm{mL}$ and more pretreatment SCC$\mathrm{Ag}$ is in association with higher FIGO stage and larger tumor size $[20,21]$. The increase of pretreatment SCC-Ag has been reported to be around $28-88 \%$, and similarly in our study $70.0 \%$ of patients diagnosed with cervical cancer showed an increase in SCC-Ag. Although there is no significant difference in median pretreatment SCC-Ag level, the proportion of patients of more than $1.5 \mathrm{ng} / \mathrm{mL}$ of pretreatment SCC-Ag level was significantly higher in patients whose prognosis was expected to be unfavorable such as high FIGO stage, large tumor size, positive lymph node involvement, and relapsed patient. Moreover the pretreatment SCC-Ag level have been found to be correlated with FIGO stage, pathology, and tumor 
Table 3. Sensitivity and specificity of biochemical recurrence in detection of clinical recurrence

\begin{tabular}{|c|c|c|}
\hline Characteristics & Sensitivity (\%) & Specificity (\%) \\
\hline All patients & 70.1 & 93.5 \\
\hline \multicolumn{3}{|l|}{ Menopausal status } \\
\hline Premenopause & 70.0 & 91.4 \\
\hline Menopause & 70.3 & 95.7 \\
\hline \multicolumn{3}{|l|}{ FIGO stage } \\
\hline । & 56.5 & 93.4 \\
\hline$\|$ & 73.8 & 95.4 \\
\hline III & 87.5 & 81.8 \\
\hline IV & 75.0 & 88.9 \\
\hline \multicolumn{3}{|l|}{ Pathology } \\
\hline SO & 77.0 & 93.8 \\
\hline$A D$ & 50.0 & 88.2 \\
\hline ASO & 50.0 & 92.3 \\
\hline \multicolumn{3}{|l|}{ Tumor size $(\mathrm{cm})$} \\
\hline$\leq 4$ & 64.9 & 95.7 \\
\hline$>4$ & 73.7 & 90.7 \\
\hline \multicolumn{3}{|c|}{ Lymph node involvement } \\
\hline Positive & 70.6 & 92.5 \\
\hline Negative & 69.2 & 94.3 \\
\hline \multicolumn{3}{|c|}{ SCC-Ag (pretreatment) } \\
\hline$<1.5$ & 35.0 & 94.8 \\
\hline$\geq 1.5$ & 82.5 & 93.9 \\
\hline \multicolumn{3}{|c|}{ Response to treatment } \\
\hline $\mathrm{CR}$ & 69.2 & 93.5 \\
\hline$P R$ & - & 87.0 \\
\hline \multicolumn{3}{|l|}{ Recurrent site } \\
\hline LRR & 63.6 & - \\
\hline DM & 71.1 & - \\
\hline$L R R+D M$ & 100 & - \\
\hline \multicolumn{3}{|l|}{ Biochemical response } \\
\hline Positive & 75.4 & 94.5 \\
\hline Negative & 41.7 & 89.0 \\
\hline
\end{tabular}

FIGO, International Federation of Gynecology and Obstetrics; SO, squamous cell carcinoma; $A D$, adenocarcinoma; $A S O$, adenosquamous cell carcinoma; $C R$, complete remission; $P R$, partial remission; LRR, locoregional recurrence; $\mathrm{DM}$, distant metastasis.

size in univariate and multivariate analysis, and biochemical response and response to treatment in univariate analysis. In this way the role of pretreatment SCC-Ag as a prognostic factor was reconfirmed in our study. The pretreatment SCC-Ag level was higher in patients with partial response to treatment, which did not show a linear relation with treatment and the relation was not statistically significant either, so pretreatment SCC-Ag was not meaningful as a predictive factor for the result of treatment. Although the proportion of more than $1.5 \mathrm{ng} / \mathrm{mL}$ pretreatment SCC-Ag level was higher in patients
Table 4. Univariate analysis of clinicopathologic factors for pretreatment and posttreatment SCC-Ag

\begin{tabular}{lcc}
\hline \multicolumn{1}{c}{ Parameter } & $\begin{array}{c}\text { SCC-Ag } \\
\text { (pretreatment) }\end{array}$ & $\begin{array}{c}\text { SCC-Ag } \\
\text { (posttreatment) }\end{array}$ \\
\hline Age & 0.005 & 0.891 \\
Menopausal status & 0.001 & 0.552 \\
Tumor size & $<0.001$ & 0.051 \\
Lymph node involvement & 0.004 & 0.912 \\
Pathology & $<0.001$ & 0.547 \\
FIGO stage & $<0.001$ & 0.465 \\
Biochemical response & $<0.001$ & 0.695 \\
Biochemical recurrence & 0.045 & 0.120 \\
Response to treatment & 0.023 & 0.099 \\
Recurrence & 0.265 & 0.826 \\
Recurrence site & 0.605 & 0.903
\end{tabular}

SCC-Ag, squamous cell carcinoma antigen; FIGO, International Federation of Gynecology and Obstetrics.

Table 5. Multivariate analysis of clinicopathologic factors for pretreatment and posttreatment SCC-Ag

\begin{tabular}{|c|c|c|c|}
\hline Parameter & $\begin{array}{c}\text { SCC-Ag } \\
\text { (pretreatment) }\end{array}$ & $\begin{array}{l}\text { Recurrence } \\
\text { of disease }\end{array}$ & $\begin{array}{l}\text { Biochemical } \\
\text { recurrence }\end{array}$ \\
\hline $\begin{array}{l}\text { Menopausal } \\
\text { status }\end{array}$ & 0.338 & 0.739 & 0.504 \\
\hline $\begin{array}{l}\text { Lymph node } \\
\text { involvement }\end{array}$ & 0.253 & 0.098 & 0.284 \\
\hline Tumor size & 0.021 & 0.076 & 0.889 \\
\hline Age & 0.842 & 0.484 & 0.377 \\
\hline FIGO stage & 0.016 & 0.069 & 0.069 \\
\hline Pathology & $<0.001$ & 0.019 & 0.567 \\
\hline $\begin{array}{c}\text { Response to } \\
\text { treatment }\end{array}$ & - & 0.034 & 0.673 \\
\hline $\begin{array}{l}\text { Biochemical } \\
\text { response }\end{array}$ & - & 0.915 & 0.351 \\
\hline $\begin{array}{l}\text { SCC-Ag } \\
\text { (pretreatment) }\end{array}$ & - & 0.466 & 0.498 \\
\hline $\begin{array}{l}\text { SCC-Ag } \\
\text { (posttreatment) }\end{array}$ & - & 0.236 & 0.003 \\
\hline
\end{tabular}

SCC-Ag, squamous cell carcinoma antigen; FIGO, International Federation of Gynecology and Obstetrics.

with positive biochemical response and statistically significant relation between pretreatment SCC-Ag with biochemical response, but there was no statistically significant relation between biochemical response and the recurrence of disease, and in survival analysis as well, 5-year DFS and OS were similar between patients showing a positive biochemical response and those showing a negative one, suggesting that biochemical 
Table 6. Five-year OS and DFS according to pretreatment SCC$\mathrm{Ag}$, biochemical response, and biochemical recurrence

\begin{tabular}{|c|c|c|c|c|}
\hline Parameter & DFS & p-value & OS & $p$-value \\
\hline \multicolumn{5}{|c|}{ SCC-Ag (pretreatment) } \\
\hline$<1.5$ & 82.3 & 0.221 & 88.5 & 0.128 \\
\hline$\geq 1.5$ & 77.9 & & 82.4 & \\
\hline \multicolumn{5}{|c|}{ Biochemical response } \\
\hline Positive & 78.4 & 0.492 & 83.6 & 0.542 \\
\hline Negative & 83.2 & & 87.1 & \\
\hline \multicolumn{5}{|c|}{ Biochemical recurrence } \\
\hline Positive & 27.6 & $<0.001$ & 53.7 & $<0.001$ \\
\hline Negative & 92.7 & & 92.5 & \\
\hline
\end{tabular}

OS, overall survival; DFS, disease free survival; SCC-Ag, squamous cell carcinoma antigen.

response is not usable as a predictive factor for treatment or as a prognostic factor for recurrence. While the pretreatment SCC-Ag level was measured low in adenocarcinoma rather than in the squamous cell type, $15.9 \%$ of adenocarcinoma patients exceeded the cutoff value and this confirmed that SCC-Ag is useful as a diagnostic tool for patients with adenocarcinoma of cervical cancer.

We calculated the sensitivity and specificity of biochemical recurrence based on clinical recurrence. Sensitivity of pretreatment SCC-Ag was significantly not different according to prognostic factors such as menopausal status, tumor size, and lymph node involvement, but was higher in the patients with higher stage, squamous cell carcinoma, high pretreatment SCC-Ag level, positive biochemical response, and concurrent LRR and DM than in the other patient groups. Thus, we concluded that if SCC-Ag increases during followup in these patients should be carried out more carefully work up for detecting locoregional recurrence as well as distant metastasis. On the contrary, in this study showed high specificity as around $90 \%$ without difference among patient groups according to most of clinicopathologic parameters. Thus, additional investigation may not be necessary unless the pretreatment SCC-Ag level increases during follow-up and it is considered beneficial in terms of cost-benefit to use an expensive or invasive diagnosis method only when the SCC-Ag level increases. Moreover biochemical recurrence significantly related with 5-year DFS and OS, so biochemical recurrence was key factor in detection of clinical recurrence and prognostic factor.

Our study reconfirmed the known function of pretreatment SCC-Ag, but could not confirm the function of biochemical response as a predictive factor for treatment and as a prognostic factor. Pathology and recurrence site did not have a significant effect on prognosis, and lastly, we confirmed the role of SCC-Ag as a follow-up tool for recurrence of disease and which patient groups SCC-Ag was more useful for.

This study has inherently limitations in retrospective research such as selection bias cannot be ignored, but its new findings in our study need to be verified through prospective largescale research in the future.

\section{Conflict of Interest}

No potential conflict of interest relevant to this article was reported.

\section{References}

1. Jemal A, Bray F, Center MM, Ferlay J, Ward E, Forman D. Global cancer statistics. CA Cancer J Clin 2011;61:69-90.

2. Benedet $J$, Odicino $F$, Maisonneuve $P$, et al. Carcinoma of the cervix uteri. J Epidemiol Biostat 2001;6:7-43.

3. Classe JM, Rauch P, Rodier JF, et al. Surgery after concurrent chemoradiotherapy and brachytherapy for the treatment of advanced cervical cancer: morbidity and outcome: results of a multicenter study of the GCCLCC (Groupe des Chirurgiens de Centre de Lutte Contre le Cancer). Gynecol Oncol 2006;102: 523-9.

4. Ferrandina $G$, Legge $F$, Fagotti $A$, et al. Preoperative concomitant chemoradiotherapy in locally advanced cervical cancer: safety, outcome, and prognostic measures. Gynecol Oncol 2007;107:S127-32.

5. Bodurka-Bevers D, Morris M, Eifel PJ, et al. Posttherapy surveillance of women with cervical cancer: an outcomes analysis. Gynecol Oncol 2000;78:187-93.

6. Lai $\mathrm{CH}$. Management of recurrent cervical cancer. Chang Gung Med J 2004;27:711-7.

7. Chou $\mathrm{HH}$, Wang $\mathrm{CC}$, Lai $\mathrm{CH}$, et al. Isolated paraaortic lymph node recurrence after definitive irradiation for cervical carcinoma. Int J Radiat Oncol Biol Phys 2001;51:442-8.

8. Micke O, Prott FJ, Schafer U, Tangerding S, Potter R, Willich N. The impact of squamous cell carcinoma (SCC) antigen in the follow-up after radiotherapy in patients with cervical cancer. Anticancer Res 2000;20:5113-5.

9. Esajas MD, Duk JM, de Bruijn HW, et al. Clinical value of routine serum squamous cell carcinoma antigen in followup of patients with early-stage cervical cancer. J Clin Oncol 2001;19:3960-6.

10. Forni F, Ferrandina G, Deodato F, et al. Squamous cell carcinoma antigen in follow-up of cervical cancer treated 
with radiotherapy: evaluation of cost-effectiveness. Int J Radiat Oncol Biol Phys 2007;69:1145-9.

11. Gadducci A, Tana R, Fanucchi A, Genazzani AR. Biochemical prognostic factors and risk of relapses in patients with cervical cancer. Gynecol Oncol 2007;107:S23-6.

12. Hirakawa $M$, Nagai $Y$, Inamine $M$, et al. Predictive factor of distant recurrence in locally advanced squamous cell carcinoma of the cervix treated with concurrent chemoradiotherapy. Gynecol Oncol 2008;108:126-9.

13. Scambia G, Benedetti Panici P, Foti E, et al. Squamous cell carcinoma antigen: prognostic significance and role in the monitoring of neoadjuvant chemotherapy response in cervical cancer. J Clin Oncol 1994;12:2309-16.

14. Reesink-Peters N, van der Velden J, Ten Hoor KA, et al. Preoperative serum squamous cell carcinoma antigen levels in clinical decision making for patients with early-stage cervical cancer. J Clin Oncol 2005;23:1455-62.

15. Molina $R$, Filella $X$, Lejarcegui JA, et al. Prospective evaluation of squamous cell carcinoma and carcinoembryonic antigen as prognostic factors in patients with cervical cancer. Tumour Biol 2003;24:156-64.

16. Ohno T, Nakayama $Y$, Nakamoto $S$, et al. Measurement of serum squamous cell carcinoma antigen levels as a predictor of radiation response in patients with carcinoma of the uterine cervix. Cancer 2003;97:3114-20.

17. Ferrandina G, Macchia G, Legge $F$, et al. Squamous cell carcinoma antigen in patients with locally advanced cervical carcinoma undergoing preoperative radiochemotherapy: association with pathological response to treatment and clinical outcome. Oncology 2008;74:42-9.

18. Ogino I, Nakayama H, Okamoto N, Kitamura T, Inoue T. The role of pretreatment squamous cell carcinoma antigen level in locally advanced squamous cell carcinoma of the uterine cervix treated by radiotherapy. Int J Gynecol Cancer 2006;16:1094-100.

19. Maiman M. The clinical application of serum squamous cell carcinoma antigen level monitoring in invasive cervical carcinoma. Gynecol Oncol 2002;84:4-6.

20. Gaarenstroom KN, Kenter GG, Bonfrer JM, et al. Can initial serum cyfra 21-1, SCC antigen, and TPA levels in squamous cell cervical cancer predict lymph node metastases or prognosis? Gynecol Oncol 2000;77:164-70.

21. Ohara K, Tanaka Y, Tsunoda H, Nishida M, Sugahara S, Itai $Y$. Assessment of cervical cancer radioresponse by serum squamous cell carcinoma antigen and magnetic resonance imaging. Obstet Gynecol 2002;100:781-7. 